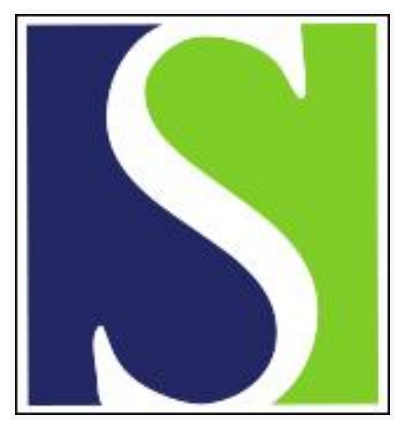

Scand J Work Environ Health 2018;44(4):377-384

https://doi.org/10.5271/sjweh.3739

Published online: 07 May 2018, Issue date: 01 Jul 2018

Enhancing the detection of injuries and near-misses among patient care staff in a large pediatric hospital

by Macaluso M, Summerville LA, Tabangin ME, Daraiseh NM

We report the results of a NIOSH-funded study demonstrating feasibility of integrating sample-based active injury surveillance into an institutional surveillance system. Whereas the healthcare industry has one of the highest rates of non-fatal occupational injury, evidence indicates these rates are underestimated, highlighting the need for improved surveillance. Enhanced surveillance provides richer information to guide development of effective injury prevention strategies.

Affiliation: Research in Patient Services; Cincinnati Children's Hospital Medical Center, 3333 Burnet Ave. Cincinnati, OH 45229, USA. MLC 7014. nancy.daraiseh@cchmc.org

Key terms: active surveillance; hospital; injury; injury detection; near-miss; occupational injury; patient care staff; pediatric hospital; pediatrics; surveillance

This article in PubMed: www.ncbi.nlm.nih.gov/pubmed/29777614 


\title{
Enhancing the detection of injuries and near-misses among patient care staff in a large pediatric hospital
}

\author{
by Maurizio Macaluso, MD, ${ }^{1}$ Lauren A Summerville, MS, ${ }^{2}$ Meredith E Tabangin, MPH, ${ }^{1}$ Nancy M Daraiseh, $P h D{ }^{1,2,3}$
}

\begin{abstract}
Macaluso M, Summerville LA, Tabangin ME, Daraiseh NM. Enhancing the detection of injuries and near-misses among patient care staff in a large pediatric hospital. Scand J Work Environ Health. 2018;44(4):377-384. doi:10.5271/sjweh.3739
\end{abstract}

\begin{abstract}
Objective Compared to other industries, healthcare has one of the highest rates of non-fatal occupational injury/ illness. Evidence indicates these rates are underestimated, highlighting the need for improved injury surveillance. This study aims to demonstrate the feasibility of integrating active data collection in a passive injury surveillance system to improve detection of injuries in a healthcare establishment.

Methods Using digital voice recorders (DVR), pediatric healthcare providers prospectively recorded events throughout their shift for two weeks. This sample-based active injury surveillance was then integrated into an institutional surveillance system (ISS) centered on passive data collection initiated by employee reports.

Results Injuries reported using DVR during two-week intervals from February 2014 to July 2015 were 40.7 times more frequent than what would be expected on the basis of the usual ISS reports. Psychological injuries (eg, stress, conflict) and near-misses were captured at a rate of 16.1 per 1000 days [95\% confidence interval (CI) 14.1-18.3] and 35.6 per 1000 days (95\% CI 32.7-38.8), respectively. Finally, 68\% (95\% CI 65-72\%) of participants preferred using DVR either as an alternative or complement to the existing ISS.

Conclusions This study showed that it is feasible to improve injury surveillance in a healthcare establishment by integrating active data collection based on voice recording within a passive injury surveillance system. Enhanced surveillance provides richer information that can guide the development of effective injury prevention strategies.
\end{abstract}

Keywords active surveillance; injury detection; occupational injury; pediatrics; surveillance.

The United States Bureau of Labor Statistics (BLS) reports that healthcare has one of the highest rates of non-fatal occupational injury/illness in industry, with US\$15 860 in average loss per claim settled (1). The Occupational Safety and Health Administration (OSHA) mandates that employers conduct surveillance of workrelated injuries/illnesses (2), but evidence indicates that BLS injury rates underestimate the true risk by up to $70 \%$, necessitating improved surveillance (3-5).

Injury under-reporting is widespread in healthcare $(4,6-11)$. One study observed that $40 \%$ of nurses would not report an injury (12). Others observed a reporting rate as low as $17 \%$ of the true value, identifying time constraints, reluctance to report, peer pressure, the "normalcy" of being injured, and reprimands as reasons for under-reporting (6-12). Attempts to enhance reporting through wellness initiatives, education, and incentives have made only minor improvements. Proactive improvements to injury reporting are needed to inform prevention strategies in healthcare.

Whereas common injury reporting systems rely on passive employee reporting (13-16), active surveillance seeks cases through direct contact with individuals (14, 17 ) or through a proactive search of medical records or databases $(14,18)$, leading to better detection of injuries (14). Despite its effectiveness, active surveillance is not commonly adopted by employers, probably because of higher resource requirements (17).

We assessed the feasibility of integrating active injury surveillance into a passive institutional surveil-

1 Biostatistics and Epidemiology; Cincinnati Children's Hospital Medical Center, Cincinnati, OH, USA.

2 James M. Anderson Center for Health Systems Excellence; Cincinnati Children's Hospital Medical Center, Cincinnati, OH, USA

3 Research in Patient Services; Cincinnati Children's Hospital Medical Center, Cincinnati, OH, USA.

Correspondence to: Nancy M Daraiseh, Research in Patient Services; Cincinnati Children's Hospital Medical Center, 3333 Burnet Ave. Cincinnati, OH 45229, USA. MLC 7014; [E-mail: nancy.daraiseh@cchmc.org] 
lance system (ISS) by comparing the frequency of injuries detected via active surveillance with the frequency reported to the ISS.

\section{Methods}

\section{Sample}

Participants comprised registered nurses (RN), patient care assistants (PCA) in medical/surgical (med/surg) and psychiatry (psych) units, and mental health specialists (MHS, assigned only to psych units) with $\geq 0.6$ full-time employment at a pediatric hospital. Med/surg units included gastroenterology/colorectal surgery, solid organ transplant, and cardiac step-down. Psych units included inpatient child, adolescent, neurological, and residential treatment.

The hospital's ISS records events reported by staff to a dedicated phone number. Call handlers ask key questions, and each call lasts $10-45$ minutes. We did not alter these operations, but added active voice recording by randomly sampling employees.

\section{Procedure}

The Institutional Review Board approved the study protocol. We collected data on sociodemographic and employment characteristics. Participants learned how to operate handheld digital voice recorders (DVR) to record near-misses or injuries sustained at work during a two-week period. Hospital policy defines an injury as "an event that inflicts physical damage as a result of an employee performing work-related duties, including any exposure to a blood-borne pathogen". We defined a nearmiss as "an incident that did not reach a staff member" (eg, trip but no fall) or "an incident that reached staff but did not cause harm" (eg, a bite by an aggressive patient that did not cause harm due to use of Kevlar gloves) (19). Participants received a laminated card with examples of injuries and near-misses. Full-time employees recorded events for six shifts and part-time staff recorded events for eight shifts. We aimed to collect recordings for 1000 two-week periods to ensure adequate precision [This sample size yields a 95\% confidence interval (CI) of $0.48 \%-1.8 \%$ for a rate of $1 \%$ ]. To assess the acceptability of active surveillance, after each interval we asked participants whether they preferred voice recording, the ISS, or a combined system. Participants were reimbursed $\$ 50$. Focus groups or interviews with 40 randomly selected participants sought feedback on effectiveness and ease-of-use of voice recording, and preferences. These participants were reimbursed $\$ 10$.

\section{Data management}

Research staff transcribed voice recordings, uploaded the transcripts into a database using NVIVO 10 (QSR International, Melbourne, Australia), and coded events as injuries or near-misses. To ensure that injury coding was comparable to that of the ISS, two members of the ISS team observed three coding sessions and advised on coding practices. At the end of the project, we selected 20 recordings representative of the range of reports and requested independent coding by the ISS team, obtaining $100 \%$ agreement.

\section{Analysis}

We followed grounded theory to develop codes from recording transcripts. Three independent coders reached consensus regarding discrepancies so that each code had a clear definition. We summarized counts of injuries and near-misses coded from the transcripts for each day in a two-week recording interval to compute incidence rates as events per 1000 days and computed 95\% CI assuming that the numerator of the rate followed the Poisson distribution. We report rates of physical and psychological injuries and near-misses according to sociodemographic and employment characteristics of the participants. We tested the association between each characteristic and physical or psychological injury rates by fitting Poisson regression models with random subject effects to account for correlation among reports of employees sampled repeatedly.

To assess the validity of active surveillance, we compared the number of events reported during the active data collection intervals with the number of events expected from the ISS. For this comparison, we used ISS data for the18-month observation period as the referent. We computed job group- and unit type-specific injury rates (per two-week period) using the ISS data, and multiplied the rate by the number of active two-week intervals in the corresponding stratum of participants. Observed-to-expected ratios measured the impact of active recording on injury detection. To test whether voice recording captured events reported to the ISS, we compared the injury reports collected by voice recording with the injuries that the same employees reported to the ISS.

We analyzed responses to the question about recording preference and compared the number of employees who prefer voice recording (including those who preferred combined digital and ISS reporting) with the number who prefer ISS reporting only, and tested the null hypothesis that the proportion preferring the ISS only was $50 \%$.

We assessed the feasibility of active surveillance using three a priori criteria: (i) over $50 \%$ of the par- 
ticipants prefer voice recording as determined from the survey question, (ii) voice recording identifies a substantial number of near-miss events $(>5$ per 100 employees/year), and (iii) the number of injury reports from voice recordings is significantly larger than the number expected from the ISS.

\section{Results}

Sampling of participants and recording periods occurred from 11 February 2014 to 31 July 2015. The majority of participants $(86 \%)$ were women, white $(81 \%),<30$ years old $(55 \%)$, with a college degree or higher education $(80 \%)$, unmarried $(61 \%)$, and without dependents (59\%) (table 1). Most were RN (72\%) in med/surg units (74\%) with a median of two years in the current job (mode $=1$, range $0-32$, mean $=3.8, \mathrm{SD}=4.5$ ). Eighteen eligible employees refused to participate: one PCA from $\mathrm{med} / \mathrm{surg}$; one MHS from psych; and $10 \mathrm{RN}$, six med/ surg and four psych. Six non-participants did not provide demographic information.

Participants reported 1043 injuries in 14762 recording days, for an average rate of 70.7 injuries/1000 days (95\% CI 66.4-75.1) (table 2). Physical injuries were most common (784 events, rate: $53.1,95 \%$ CI $49.5-$ 57.0). Common physical injuries were musculoskeletal (eg, low-back and shoulder pain); due to patient aggression (eg, patient pinched, punched, kicked or bit staff); or falls to the floor. Although psychological injuries are rarely reported through the ISS, active surveillance detected 238 events for an average rate of 16.1 injuries/1000 days (95\% CI 14.1-18.3). Finally, 526 nearmisses were recorded (rate: $35.6,95 \%$ CI $32.7-38.8$ ), most referring to potential physical harm (table 2). Common near-misses included: patient trying to hit staff without contact and staff tripping but not falling. We limit the further presentation of results to injuries.

Physical injury rates varied by baseline characteristics (table 3): staff between 30-34 years of age (95.4, 95\% CI 84.2-107.8) and women (57.4, 95\% CI 53.3-61.8) had relatively high rates, whereas AfricanAmerican employees experienced lower rates (23.0, 95\% CI 16.8-30.7) compared to other groups. The incidence of physical injuries increased with level of education and was highest among employees with postgraduate education (107.3, 95\% CI 90.0-127.0). Rates were high among employees who never married (69.1, 95\% CI 63.3-75.3) or had no dependents $(70.4,95 \% \mathrm{CI}$ 64.9-76.2). Physical injury rates were similar in psych units and $\mathrm{med} / \mathrm{surg}$ units, and PCA experienced lower rates than the other job groups (23.9, 95\% CI 17.8-31.3). Physical injury rates were significantly associated with all characteristics except unit of employment.
Table 1. Sociodemographic and employment characteristics of the study. Group at baseline $(\mathrm{N}=607)$

\begin{tabular}{|c|c|c|}
\hline & $\mathrm{N}$ & $\%$ \\
\hline \multicolumn{3}{|l|}{ Gender } \\
\hline Male & 75 & 12 \\
\hline Female & 522 & 86 \\
\hline Missing & 10 & 2 \\
\hline \multicolumn{3}{|l|}{ Age (years) } \\
\hline$<25$ & 144 & 24 \\
\hline $25-29$ & 189 & 31 \\
\hline $30-34$ & 106 & 17 \\
\hline $35-44$ & 90 & 15 \\
\hline$\geq 45$ & 61 & 10 \\
\hline \multicolumn{3}{|l|}{ Race/ethnicity } \\
\hline Non-Hispanic white & 493 & 81 \\
\hline Non-Hispanic black & 76 & 13 \\
\hline Other groups & 23 & 4 \\
\hline \multicolumn{3}{|l|}{ Education } \\
\hline High school & 5 & 1 \\
\hline Associate/vocational & 43 & 7 \\
\hline Some college & 74 & 12 \\
\hline College degree & 423 & 70 \\
\hline Post-graduate & 61 & 10 \\
\hline \multicolumn{3}{|l|}{ Marital status } \\
\hline Never married & 316 & 52 \\
\hline Married & 240 & 39 \\
\hline Divorced/separated & 37 & 6 \\
\hline Widow & 2 & $<1$ \\
\hline \multicolumn{3}{|l|}{ Dependents } \\
\hline No & 357 & 59 \\
\hline Yes & 236 & 39 \\
\hline \multicolumn{3}{|l|}{ Current position } \\
\hline Registered nurse & 437 & 72 \\
\hline Mental health specialist & 81 & 13 \\
\hline Patient care attendant & 89 & 15 \\
\hline \multicolumn{3}{|l|}{ Shift type } \\
\hline 8-hour & 187 & 31 \\
\hline 12-hour & 242 & 40 \\
\hline Both 8-and 12-hour & 177 & 29 \\
\hline Other schedules & 1 & $<1<-1$ \\
\hline \multicolumn{3}{|l|}{ Unit of employment } \\
\hline Medical-surgical & 447 & 74 \\
\hline Psychiatry & 160 & 26 \\
\hline Years in current position a & 601 & \\
\hline
\end{tabular}

Table 2. Incident injury and near-misses. N=14 762 recording days, $\mathrm{N}=927$ two-week recording intervals. [Cl=confidence interval]

\begin{tabular}{lccr}
\hline Event type & $\begin{array}{c}\text { Injuries } \\
\text { reported }\end{array}$ & $\begin{array}{c}\text { Rate } \\
\text { per 1000 days }\end{array}$ & \multicolumn{1}{c}{$95 \% \mathrm{Cl}$} \\
\hline All injuries combined & 1043 & 70.7 & $66.4-75.1$ \\
Physical & 784 & 53.1 & $49.5-57.0$ \\
Psychological & 238 & 16.1 & $14.1-18.3$ \\
Bodily fluid exposure & 21 & 1.4 & $0.9-2.2$ \\
All near-misses combined & 526 & 35.6 & $32.7-38.8$ \\
Physical & 480 & 32.5 & $29.7-35.6$ \\
Bodily fluid exposure & 38 & 2.6 & $1.8-3.5$ \\
Other & 8 & 0.5 & $0.2-1.0$ \\
\hline
\end{tabular}

Psychological injury rates were higher among women than men, increased with age, from 7.5 (95\% CI $4.9-11.0)$ in the youngest group to $33.5(95 \% \mathrm{CI}$ 25.2-43.7) in the oldest. The incidence of psychological injuries was not associated with race/ethnicity, education, marital status or with having dependents, but rates 
Table 3. Physical and psychological incident injuries (rate per 1000 days). $\mathrm{N}=14762$ recording days, $\mathrm{N}=927$ two-week recording intervals. [Cl=confidence interval]

\begin{tabular}{|c|c|c|c|c|c|c|}
\hline \multirow[t]{2}{*}{ Characteristic } & \multicolumn{3}{|c|}{ Physical injuries ${ }^{a}$} & \multicolumn{3}{|c|}{ Psychological injuries } \\
\hline & Events reported & Rate $(95 \% \mathrm{Cl})$ & P-value ${ }^{b}$ & Events reported & Rate $(95 \% \mathrm{Cl})$ & P-value ${ }^{b}$ \\
\hline \multicolumn{7}{|l|}{ Gender } \\
\hline Male & 94 & $44.4(36.2-54.3)$ & 0.02 & 27 & $12.7(8.7-18.6)$ & 0.15 \\
\hline Female & 710 & $57.4(53.3-61.8)$ & & 209 & $16.9(14.8-19.4)$ & \\
\hline \multicolumn{7}{|l|}{ Age (years) } \\
\hline$<25$ & 151 & 43.7 (37.3-51.3) & $<0.0001$ & 26 & $7.5(5.1-11.1)$ & $<0.0001$ \\
\hline $25-29$ & 237 & $54.0(47.5-61.3)$ & & 57 & $13.0(10.0-16.8)$ & \\
\hline $30-34$ & 259 & 95.4 (84.5-107.8) & & 42 & $15.5(11.4-20.9)$ & \\
\hline $35-44$ & 90 & $41.5(33.8-51.1)$ & & 57 & $26.3(20.3-34.1)$ & \\
\hline$\geq 45$ & 57 & $35.4(27.3-45.9)$ & & 54 & $33.5(25.7-43.8)$ & \\
\hline \multicolumn{7}{|l|}{ Race/ethnicity } \\
\hline Non-Hispanic white & 722 & $60.9(56.5-65.5)$ & $<0.0001$ & 185 & $15.6(13.5-18.0)$ & 0.15 \\
\hline Non-Hispanic black & 46 & $23.0(17.2-30.7)$ & & 36 & $18.0(13.0-25.0)$ & \\
\hline Other groups & 34 & $60.6(43.3-84.8)$ & & 15 & $26.7(16.1-44.4)$ & \\
\hline \multicolumn{7}{|l|}{ Education } \\
\hline High school & 3 & $29.1(9.4-90.3)$ & $<0.0001$ & 0 & & 0.04 \\
\hline Associate/vocational & 38 & $36.4(26.5-50.0)$ & & 16 & $15.3(9.4-25.0)$ & \\
\hline Some college & 76 & $41.5(33.1-51.9)$ & & 40 & $21.8(16.0-29.8)$ & \\
\hline College degree & 551 & $53.6(49.3-58.3)$ & & 152 & $14.8(12.6-17.3)$ & \\
\hline Post-graduate & 136 & $107.3(90.7-127.0)$ & & 30 & $23.7(16.6-33.9)$ & \\
\hline \multicolumn{7}{|l|}{ Marital status } \\
\hline Never married & 520 & $69.1(63.4-75.3)$ & $<0.0001$ & 119 & $15.8(13.2-18.9)$ & 0.76 \\
\hline Married & 257 & $43.7(38.6-49.4)$ & & 100 & $17.0(14.0-20.7)$ & \\
\hline Divorced/separated & 27 & $25.7(17.6-37.5)$ & & 16 & $15.2(9.3-24.9)$ & \\
\hline Widow & 0 & & & 1 & $47.6(6.7-338.0)$ & \\
\hline \multicolumn{7}{|l|}{ Dependents } \\
\hline Yes & 192 & $33.6(29.2-38.7)$ & $<0.0001$ & 101 & $17.7(14.6-21.5)$ & 0.32 \\
\hline No & 612 & $70.4(65.0-76.2)$ & & 135 & $15.5(13.1-18.4)$ & \\
\hline \multicolumn{7}{|l|}{ Current position } \\
\hline Registered nurse & 608 & $60.1(55.5-65.1)$ & $<0.0001$ & 178 & $17.6(15.2-20.4)$ & 0.0009 \\
\hline Mental health specialist & 144 & $64.2(54.6-75.6)$ & & 43 & $19.2(14.2-25.9)$ & \\
\hline Patient care attendant & 52 & $23.9(18.2-31.3)$ & & 17 & $7.8(4.8-12.5)$ & \\
\hline \multicolumn{7}{|l|}{ Unit of employment } \\
\hline Medical-surgical & 579 & $55.8(51.5-60.6)$ & 0.68 & 115 & $11.1(9.2-13.3)$ & $<0.0001$ \\
\hline Psychiatry & 225 & $54.0(47.4-61.6)$ & & 123 & $29.5(24.8-35.2)$ & \\
\hline
\end{tabular}

a Includes exposure to bodily fluids.

${ }^{\mathrm{b}}$ Test of the null hypothesis of no association between the characteristic and the injury rates.

were considerably higher in psych units $(29.5,95 \% \mathrm{CI}$ 24.6-35.2) than in med/surg units. PCAs experienced considerably lower rates of psychological injuries than the other job groups (7.8, 95\% CI 4.5-12.5). Psychological injury rates were significantly associated with age, education, job group and unit of employment.

The comparison of counts of injuries reported by voice recording with counts expected from the ISS excluded psychological injuries because these are not routinely reported to the ISS. The number of injuries reported using DVR was 40.7 times higher than that expected on the basis of the ISS (table 4). Statistically significant observed-to-expected injury ratios ranged from about 6 for $\mathrm{RN}$ in psych units $(6.4,95 \% \mathrm{CI}$ 5.1-8.1) to $>100(108.4,95 \%$ CI $99.4-118.1)$ for RNs in $\mathrm{med} / \mathrm{surg}$ units. All were significantly larger than the null value of 1 .

We identified 45 incidents that were reported to the ISS and detected 41 matching reports (91\%). Thus, active reporting captured nearly all incidents reported to the ISS. The 4 events missed by the recordings were; a near-miss (needle-stick); a blood-borne pathogen expo- sure; a pregnant employee exposed to the parvovirus $\mathrm{B} 19$; and a pulled hamstring.

We surveyed participants at the end of the first recording period $(\mathrm{N}=557)$ on their reporting preference. A total of $161(29 \%)$ stated that they preferred voice recording; 174 (31\%) preferred the ISS; and 219 (39\%) thought that both systems were necessary to capture injuries and near-misses. Thus, 68\% (95\% CI 65-72\%) preferred using the DVR as an alternative or a complement to the ISS, a significantly larger proportion than the null value of $50 \%(\mathrm{P}<0.0001)$. A total of 199 employees participated in more than one recording period. The proportion of those who preferred digital recording alone or integrated with the ISS increased from $71.7 \%$ at the first survey to $78.3 \%$ at the second.

The focus group or interview comprised 5 men and 35 women, 20 participants from psych and 20 from med/ surg units; 16 individuals participated in six groups, but difficulties in removing staff from units resulted in 24 one-on-one interviews. Participants reported that they were able to use DVR to capture some or all injuries (56\%), near-misses (49\%), and psychological injuries 
Table 4. Incident injuries reported by voice recording (observed). Numbers expected on the basis of ISS rates. $\mathrm{N}=14762$ recording days and $\mathrm{N}=927$ two-week recording intervals. [0/E= observed/expected ratio, test of the null hypothesis that $0 / \mathrm{E}=1 ; \mathrm{Cl}=$ confidence interval; MHS=mental health specialist: $P C A=$ patient care attendant; $\mathrm{RN}=$ registered nurse.]

\begin{tabular}{llrrrrr}
\hline $\begin{array}{l}\text { Job } \\
\text { group }\end{array}$ a & $\begin{array}{l}\text { Work } \\
\text { area }\end{array}$ & Observed & Expected & O/E & \multicolumn{1}{l}{$95 \% \mathrm{Cl}$} & P-value \\
\hline All & All & 805 & 19.8 & 40.7 & $37.9-43.6$ & $<0.0001$ \\
All & Med/Surg & 579 & 5.4 & 106.5 & $92.0-115.5$ & $<0.0001$ \\
All & Psych & 225 & 30.5 & 7.4 & $6.4-8.4$ & $<0.0001$ \\
MHS & Psych & 144 & 18.9 & 7.6 & $6.4-9.0$ & $<0.0001$ \\
PCA & All & 52 & 0.94 & 55.1 & $41.1-72.3$ & $<0.0001$ \\
PCA & Med/Surg & 48 & 0.68 & 70.0 & $51.6-92.9$ & $<0.0001$ \\
PCA & Psych & 4 & 0.48 & 8.3 & $2.2-21.2$ & 0.002 \\
RN & All & 608 & 9.6 & 63.1 & $58.2-68.3$ & $<0.0001$ \\
RN & Med/Surg & 531 & 4.9 & 108.4 & $99.4-118.1$ & $<0.0001$ \\
RN & Psych & 77 & 11.9 & 6.4 & $5.1-8.1$ & $<0.0001$ \\
\hline
\end{tabular}

(30\%) with $40 \%$ preferring voice recording to the ISS. The underestimation of psychological harm is understandable as healthcare providers are not accustomed to reporting these types of outcomes. Ninety percent stated that using DVR did not impede their work and were not bulky or hard to use $(83 \%, \mathrm{~N}=29)$. When asked about barriers to voice recording, respondents cited the difficulty of finding the right time or place to record during their shift or forgetting to record. Some participants mentioned the convenience of recording at the end of the shift, while others found it feasible during work hours. Finally, when asked if they preferred to call a live person, respondents mentioned that the ISS would be less likely to capture minor incidents ("I think that if your requirement would be a call you would probably pick up less of the very small things...") but would be necessary to discuss serious injuries ("... if it was a huge event clearly I would want to speak to another human being... I felt like I wanted some advice of what I needed to do about that injury") (table 5).

\section{Discussion}

In 2010, the healthcare and social assistance industry reported more injuries and illnesses than any other private industry sector (20). Healthcare providers, however, frequently under-report work environment hazards and injuries, so improving injury surveillance should be a high priority in this sector. We assessed the feasibility of integrating sample-based active injury surveillance into our passive ISS and showed that pediatric healthcare providers experience a high frequency of injuries that they do not report to the ISS. Pompeii et al (21) observed that workers report workplace violence informally to coworkers, managers, and in patient medical records, but not in not in OSHA-mandated reporting systems.
Table 5. Key questions addressed in focus groups and qualitative interviews, with representative answers.

Q: Were there barriers to reporting?

"The barriers would probably be just finding somewhere quiet or somewhere where you don't have all of the commotion going on in the background. So I used to go in the bathroom most of the times. Just wait till everybody clears out the staff office, but then literally you would have to wait for that to happen."

"Um, not for me personally, but I know like our floor is very high acuity so it's very busy. So I don't know, there could have been times when nurses didn't have time to record right away just from the, you know, the nature of the work."

"Um, no, no barriers beyond, you know, my own forgetfulness."

$\mathrm{Q}$ : Did you develop a pattern of recording?

"I did it more at the end of the day, just time frame and everything like that."

"No, not easy to record when they happened. But I don't feel like I, I don't think I actually forgot to do it at the end of the day or at the beginning, but not when it happened......Um, looking back at the day and recording."

"I would tend to record in between, like if I had some down time, especially when I was charting I would try to record and then kind of like recap at the end of the day."

Q: Do you prefer speaking to an actual person when recording a near-miss or injury?

"I think that if your requirement would be a call you would probably pick up less of the very small things where I'm like I don't know if this is worth an entire phone call. Whereas I might record it on the recorder if it's just in my pocket and it's going to take ten seconds to do it."

"Um, yeah. And I think that there's certain instances in which like if it was a huge event clearly I would want to speak to another human being.

"It would depend on the injury and I felt like I wanted some advice of what I needed to do about that injury. If it was just a simple injury that I was recording because I was worried I would wake up tomorrow and something hurt, recording into, a non-person would be fine. But if I actually knew that I got injured I would want to talk to a real person."

The average employee in our population experiences 26 injuries/year, 19 physical and 6 psychological, and 13 near-misses/year. The number of physical injuries reported through active voice recording is over 40 times higher than the number expected in the same timeframe according to the ISS.

We found significant associations between the incidence of injuries and several demographic and employment variables. Interestingly, injury risk increased with increasing educational level. It is possible that more educated employees are assigned to riskier tasks (eg, care of complex patients). It is also possible that the more educated participants reported injuries more accurately. Other studies show inconsistent associations between injury rates and education (22): thus, this issue warrants further research.

Although it is known that active surveillance is more accurate than passive surveillance $(13,15,16)$, the vast difference we observed is surprising. We aligned our coding methods to the ISS and observed high concordance in evaluations of the recording transcripts: thus, misclassification of non-injury events as injuries is unlikely. Busy employees may under-report to avoid discussing details in lengthy phone calls, as noted in our focus groups/interviews. Such a large number of unreported incidents may reduce productivity, increase 
use of sick-leave, and cause adverse health effects and turnover among the employees, as one participant stated: "Speaking from personal experience I can say that I, uh, I had to go out and seek therapeutic intervention in the community due to a long series of near misses...I would say that was a large factor in why I'm now in out-patient $\mathrm{med} /$ surg versus still in psychiatry."

We established the feasibility of integrating the ISS with sample-based active surveillance using three criteria. First, voice recording is acceptable to employees. More than $50 \%$ of the participants $(68 \%, \mathrm{P}<0.0001)$ prefer using the DVR as an alternative or a complement to the ISS. Second, voice recording detects a sufficient number of near-misses - 36/1000 days or $1314 / 100$ employees/year. Third, the system detects over 40 times more injuries than the ISS. These findings indicate that integrating our ISS with sample-based active surveillance would improve injury surveillance at our institution. Our focus groups/interviews showed staff support for using DVR to record injuries and near-misses. Feasibility of active surveillance is historically supported by experience with adverse drug reactions (23-25), which resulted in an increase in reported cases (27). Dement et al (27) integrated active and passive methods to improve a surveillance system.

Prior to this work, few studies assessed the risk of injury in pediatric healthcare (28-34). Contrary to the belief that the pediatric work environment is safer than the adult counterpart $(32,34)$, pediatric providers have comparable injury rates, with physical injuries comprising $75 \%$ of all reports. Musculoskeletal disorder rates in adult care vary from $43-63 \%(35-37)$ and may be as high as $89 \%$ (38). Psychological injuries were also common in the few studies that addressed the topic $(38,39)$.

Measuring the incidence of near-misses has theoretical advantages: increased potential to identify causal pathways leading to injury; increased acceptability of reporting an event without actual injury to patient or worker; and reduced concern that the employee may be at fault. Reporting near-misses has long been integrated in high-risk industries such as aviation and nuclear power (40-42) because each occurrence can identify failures in systems, equipment, and processes that may lead to injury $(12,40,42-44)$. Our findings indicate that voice recording is an effective surveillance method that can produce rich information on near-misses.

Stressful workplace conditions cause psychological injury, which in turn may increase the risk of physical harm, reduce attendance and productivity, and may cause medical errors, threatening the safety of patients. We included stress, anxiety, fear, intimidation, bullying, and conflict as psychological injuries to be reported. The incidence of 16.1 events/1000 days indicates that these outcomes are common and employees are willing to report them. Neither near-misses nor psychological injuries are routinely captured by surveillance systems in healthcare.

This study had some limitations. First, no gold standard was available to assess the validity of the active surveillance. We do not know the true incidence of injuries and near-misses in the population studied and cannot measure the accuracy of our methods. The large number of events detected by voice recording, however, indicates that active surveillance is superior to the ISS. Second, our data do not allow for assessing injury severity, and we could not identify OSHA-recordable events. Comparison of OSHA-recordable events detected by active surveillance with those detected by the ISS would provide stronger evidence. We did confirm that most of the injuries reported to the ISS had matching reports in the voice recordings. Third, although we used rigorous feasibility criteria, we did not evaluate the cost/sustainability of active surveillance. Cost estimation should include the impact of improved injury detection on the institutional ability to strengthen employee safety programs. We provided an overview of the results but did not evaluate associations with specific risk factors to make causal inference. We note that implementation of this sample-based active surveillance system shows statistically significant variation of risk according to participant characteristics, indicating that in-depth analyses of the data will be informative and facilitate the development of strategies to reduce risk.

The limitations mentioned above are offset by important strengths. To our knowledge, no previous studies have evaluated an active data collection process simultaneously with passive detection of injury cases, allowing for a direct comparison. Second, we were able to compute incidence rates, and future reports will assess the impact of specific risk factors on the incidence of injuries and near misses. In addition, we were able to assess the frequency of psychological injuries and nearmisses, both of which escape detection through current systems. Finally, we found that employees are willing to use DVR to detect outcomes and potential risk factors.

\section{Concluding remarks}

It is feasible to integrate a passive ISS with active data collection using voice recording. The latter provides rich information that can assist the development of more effective injury prevention strategies. Sample-based active surveillance may make be more acceptable to staff and more affordable for the institution. Reporting near-misses and psychological injuries further enriches the system. 


\section{Acknowledgments}

This work was supported by the Centers of Disease Control and Prevention - National Institute for Occupational Health and Safety (1R21OH010035-01A1). The content is solely the responsibility of the authors and does not necessarily represent the official views of the Centers of Disease Control and Prevention or the United States government.

\section{References}

1. US Department of Labor Bureau of Labor Statistics. News release: Lost-worktime injuries and illnesses: characteristics and resulting days ways from work, 2015 [Internet]. 2016. Available from: https://www.bls.gov/news.release/pdf/osh2. pdf.

2. Occupational Safety and Health Administration United States Department of Labor. Employer Responsibilities. 1970.

3. Rosenman KD, Kalush A, Reilly MJ, Gardiner JC, Reeves $\mathrm{M}$, Luo Z. How much work-related injury and illness is missed by the current national surveillance system? J Occup Environ Med 2006 Apr;48(4):357-65. http://dx.doi. org/10.1097/01.jom.0000205864.81970.63.

4. Menzel NN. Underreporting of musculoskeletal disorders among health care workers: research needs. AAOHN J 2008 Dec;56(12):487-94. http://dx.doi.org/10.3928/0891016220081201-06.

5. Ruser JW. Examining evidence on whether BLS undercounts workplace injuries and illnesses. Mon Labor Rev 2008;131:20.

6. Pransky G, SnyderT, Dembe A, Himmelstein J.Under-reporting of work-related disorders in the workplace: a case study and review of the literature. Ergonomics 1999 Jan;42(1):171-82. http://dx.doi.org/10.1080/001401399185874.

7. Siddharthan K, Hodgson M, Rosenberg D, Haiduven D, Nelson A. Under-reporting of work-related musculoskeletal disorders in the Veterans Administration. Int J Health Care Qual Assur Inc Leadersh Health Serv 2006;19(6-7):463-76. http://dx.doi.org/10.1108/09526860610686971.

8. Blegen MA, Vaughn T, Pepper G, Vojir C, Stratton K, Boyd $\mathrm{M}$ et al. Patient and staff safety: voluntary reporting. Am J Med Qual 2004 Mar-Apr;19(2):67-74. http://dx.doi. org/10.1177/106286060401900204.

9. Gropelli T, Corle K. Assessment of nurses' and therapists' occupational musculoskeletal injuries. Medsurg Nurs 2011 Nov-Dec;20(6):297-303.

10. Shannon HS, Lowe GS. How many injured workers do not file claims for workers' compensation benefits? Am J Ind Med 2002 Dec;42(6):467-73. http://dx.doi.org/10.1002/ ajim. 10142 .
11. Fagan KM, Hodgson MJ. Under-recording of work-related injuries and illnesses: an OSHA priority. J Safety Res 2017 Feb;60:79-83. http://dx.doi.org/10.1016/j.jsr.2016.12.002.

12. Brown JG, Trinkoff A, Rempher K, McPhaul K, Brady B, Lipscomb J et al. Nurses' inclination to report work-related injuries: organizational, work-group, and individual factors associated with reporting. AAOHN J 2005 May;53(5):213-7.

13. Benavides FG, Delclos GL, Cooper SP, Benach J. Comparison of fatal occupational injury surveillance systems between the European Union and the United States. Am J Ind Med 2003 Oct;44(4):385-91. http://dx.doi. org/10.1002/ajim.10290.

14. German RR, Lee LM, Horan JM, Milstein RL, Pertowski CA, Waller MN; Guidelines Working Group Centers for Disease Control and Prevention (CDC). Updated guidelines for evaluating public health surveillance systems: recommendations from the Guidelines Working Group. MMWR Recomm Rep 2001 Jul;50 RR-13:1-35.

15. Vogt RL, LaRue D, Klaucke DN, Jillson DA. Comparison of an active and passive surveillance system of primary care providers for hepatitis, measles, rubella, and salmonellosis in Vermont. Am J Public Health 1983 Jul;73(7):795-7. http://dx.doi.org/10.2105/AJPH.73.7.795.

16. Smith CS, Silverman GS, Heckert TM, Brodge MH, Hayes BE, Silverman MK, et al. A Comprehensive method for the assessment of industrial injury events. J Prev Intervent Community 2001;22(1):5-20. http://dx.doi. org/10.1080/10852350109511207.

17. Holder Y, Peden M, Krug E, Lund J, Gururaj G, Kobusingye O. Injury surveillance guidelines. World Health Organization; 2002.

18. World Health Organization. Health Topics: Public Health Surveillance [Internet]. 2018. Available from: http://www. who.int/topics/public_health_surveillance/en/.

19. Kessels-Habraken M, Van der Schaaf T, De Jonge J, Rutte C Defining near misses: towards a sharpened definition based on empirical data about error handling processes. Soc Sci Med 2010 May;70(9):1301-8. http://dx.doi.org/10.1016/j. socscimed.2010.01.006.

20. Occupational Safety and Health Administration. Safety and Health Topics: Healthcare [Internet]. 2016. Available from: https://www.osha.gov/SLTC/healthcarefacilities/index. html.

21. Pompeii L, Dement J, Schoenfisch A, Lavery A, Souder M, Smith C et al. Perpetrator, worker and workplace characteristics associated with patient and visitor perpetrated violence (Type II) on hospital workers: a review of the literature and existing occupational injury data. $\mathrm{J}$ Safety Res 2013 Feb;44:57-64. http://dx.doi.org/10.1016/j. jsr.2012.09.004.

22. Cubbin C, LeClere FB, Smith GS. Socioeconomic status and the occurrence of fatal and nonfatal injury in the United States. Am J Public Health 2000 Jan;90(1):70-7. http:// dx.doi.org/10.2105/AJPH.90.1.70.

23. Carleton B, Poole R, Smith M, Leeder J, Ghannadan R, Ross 
C et al. Adverse drug reaction active surveillance: developing a national network in Canada's children's hospitals. Pharmacoepidemiol Drug Saf 2009 Aug;18(8):713-21. http://dx.doi.org/10.1002/pds.1772.

24. Huang YL, Moon J, Segal JB. A comparison of active adverse event surveillance systems worldwide. Drug Saf 2014 Aug;37(8):581-96. http://dx.doi.org/10.1007/s40264014-0194-3.

25. Szekendi MK, Sullivan C, Bobb A, Feinglass J, Rooney $\mathrm{D}$, Barnard $\mathrm{C}$ et al. Active surveillance using electronic triggers to detect adverse events in hospitalized patients. Qual Saf Health Care 2006 Jun;15(3):184-90. http://dx.doi. org/10.1136/qshc.2005.014589

26. Teutsch S, Lee L, Teutsch S, Thacker S, St Louise M. Considerations in planning a surveillance system. Principles and Practice of Public Health Surveillance. 2010:18. http:// dx.doi.org/10.1093/acprof:oso/9780195372922.001.0001.

27. Dement JM, Pompeii LA, Østbye T, Epling C, Lipscomb HJ, James $\mathrm{T}$ et al. An integrated comprehensive occupational surveillance system for health care workers. Am J Ind Med 2004 Jun;45(6):528-38. http://dx.doi.org/10.1002/ ajim.20017.

28. Dworsky ME, Welch K, Cassady G, Stagno S. Occupational risk for primary cytomegalovirus infection among pediatric health-care workers. N Engl J Med 1983 Oct;309(16):950-3. http://dx.doi.org/10.1056/NEJM198310203091604.

29. Sobaszek A, Fantoni-Quinton S, Frimat P, Leroyer A, Laynat A, Edme JL. Prevalence of cytomegalovirus infection among health care workers in pediatric and immunosuppressed adult units. J Occup Environ Med 2000 Nov;42(11):1109-14. http://dx.doi.org/10.1097/00043764200011000-00015.

30. Flowers RH 3rd, Torner JC, Farr BM. Primary cytomegalovirus infection in pediatric nurses: a meta-analysis. Infect Control Hosp Epidemiol 1988 Nov;9(11):491-6. http://dx.doi. org/10.2307/30146544.

31. Carlier P, Vanderbecken F, Szpalski M, Hayez JP. Isoinertial functional assessment of low-back disorders in pediatric nurses: ergonomic and rehabilitation guidelines. J Occup Rehabil 1992 Sep;2(3):131-8. http://dx.doi.org/10.1007/ BF01077185.

32. Boden LI, Sembajwe G, Tveito TH, Hashimoto D, Hopcia $\mathrm{K}$, Kenwood $\mathrm{C}$ et al. Occupational injuries among nurses and aides in a hospital setting. Am J Ind Med 2012 Feb;55(2):117-26. http://dx.doi.org/10.1002/ajim.21018.

33. Jagger J, Perry J. Protecting pediatric nurses. Nursing 1999 Dec;29(12):81. http://dx.doi.org/10.1097/00152193199929120-00047.
34. Rodríguez-Acosta RL, Richardson DB, Lipscomb HJ, Chen JC, Dement JM, Myers DJ et al. Occupational injuries among aides and nurses in acute care. Am J Ind Med 2009 Dec;52(12):953-64. http://dx.doi.org/10.1002/ajim.20762.

35. Alexopoulos EC, Tanagra D, Detorakis I, Gatsi P, Goroyia A, Michalopoulou M et al. Knee and low back complaints in professional hospital nurses: occurrence, chronicity, care seeking and absenteeism. Work 2011;38(4):329-35.

36. Black TR, Shah SM, Busch AJ, Metcalfe J, Lim HJ. Effect of transfer, lifting, and repositioning (TLR) injury prevention program on musculoskeletal injury among direct care workers. J Occup Environ Hyg 2011 Apr;8(4):226-35. http:// dx.doi.org/10.1080/15459624.2011.564110.

37. Davis KG, Kotowski SE. Prevalence of Musculoskeletal Disorders for Nurses in Hospitals, Long-Term Care Facilities, and Home Health Care: A Comprehensive Review. Hum Factors 2015 Aug;57(5):754-92. http://dx.doi. org/10.1177/0018720815581933.

38. Ribeiro T, Serranheira F, Loureiro H. Work related musculoskeletal disorders in primary health care nurses. Appl Nurs Res 2017 Feb;33:72-7. http://dx.doi. org/10.1016/j.apnr.2016.09.003.

39. Alamgir H, Cvitkovich Y, Yu S, Yassi A. Work-related injury among direct care occupations in British Columbia, Canada. Occup Environ Med 2007 Nov;64(11):769-75. http://dx.doi.org/10.1136/oem.2006.031914.

40. Barach P, Small SD. Reporting and preventing medical mishaps: lessons from non-medical near miss reporting systems. BMJ 2000 Mar;320(7237):759-63. http://dx.doi. org/10.1136/bmj.320.7237.759.

41. Chapanis A. Research techniques in human engineering. Baltimore: Johns Hopkins Press; 1959.

42. Alamgir H, Yu S, Gorman E, Ngan K, Guzman J. Near miss and minor occupational injury: does it share a common causal pathway with major injury? Am J Ind Med 2009 Jan;52(1):69-75. http://dx.doi.org/10.1002/ajim.20641.

43. Clarke SP, Rockett JL, Sloane DM, Aiken LH. Organizational climate, staffing, and safety equipment as predictors of needlestick injuries and near-misses in hospital nurses. Am J Infect Control 2002 Jun;30(4):207-16. http://dx.doi. org/10.1067/mic.2002.123392.

44. Jones S, Kirchsteiger C, Bjerke W. The importance of near miss reporting to further improve safety performance. J Loss Prev Process Ind 1999;12:59-67. http://dx.doi.org/10.1016/ S0950-4230(98)00038-2.

Received for publication: 10 November 2017 